\title{
Development Finite State Machine Agent in Edugame "Hangug Word" Learning Media of Korea Hangul Letters
}

\author{
Nursobah $^{1, *}$, Reza Andrea ${ }^{2}$, Bambang Kurniawan ${ }^{1}$ \\ ${ }^{1}$ STMIK Widya Cipta Dharma, Samarinda, Indonesia \\ ${ }^{2}$ Polytechnic Agricultural of Samarinda, Samarinda, Indonesia \\ Email: 1," nursobah2011@ gmail.com, ${ }^{2}$ reza@ bbirdesign.com, ${ }^{3}$ brsyn99@ gmail.com \\ Correspondence Author Email: nursobah2011@gmail.com
}

\begin{abstract}
Development the edugame "Hangug Word", learning media of to Korean Hangul letters with game Agent Finite State Machine based on Android. The application used in making the game is Swish max4. In this game, a game agent character is given. In the game agent using the Finite State Machine (FSM) method, the Game Agent will notify the players if they answer incorrectly or correctly in the game. The Finite State Machine method of designing a control system that describes the working principle of the system using three things: state, event, action used in the game agent can provide action and reaction to players when the game is played. The results of making this edugame are .Apk and .Swf which can be run on an Android smartphone.
\end{abstract}

Keywords: Edugame; Hangul; Android; Game Agent; Finite State Machine

\section{INTRODUCTION}

The Korean language in Indonesia a few years ago was not something that was interesting, but nowadays Korean language has an important role in international relations [1,2]. This can be seen with the incessant economic attacks and the Hallyu (Korean Wave) making Korean a language that is in great demand and is taken into account $[1,3]$. For example, five years ago, there were still a few Korean series broadcast on Indonesian television stations, only two to three series were broadcast in one year, and no Korean boy band or girl group had concerts in Indonesia [4]. Then from 2010 until now, Korean series and songs began to be in demand by many people [5-7]. Television stations in Indonesia began to broadcast Korean series frequently, such as Boys Before Flower, City Hunter, 49 Days, Dream High, and many more.

To participate in the Korean Wave in Indonesia, people began to learn Korean [7]. However, the Korean language learning media is currently less interactive so it doesn't attract attention from the public [2]. This is because the limited means of learning Korean through books make it difficult for most people who are interested in Korean to learn Korean [5,7]. Learning through books is considered less interactive because there are no voice facilities for Korean pronunciation [9]. Learning using a mobile application is considered to be more interactive and fun, because it is supported by an attractive design and a voice for Korean pronunciation. To keep up with these developments, a tool that can be used to assist in learning Korean is made. Namely a combination of basic Korean language lessons and application programs on the Android platform. The application that will be made contains Korean letters (Hangeul). Based on the description, we wants to build an Edugame "Hangug Word". Learning media of Korean Hangul Letters with an Android-based Agent Finite State Machine Game which can be an interesting place for entertainment and learning and aims to recognize Hangul letters.

Edugame(educational game), very interesting to develop [10-15]. Because by playing educational games on any platform, they will indirectly learn something knowledge in the form of a game [11,13]. In this game, the game agent (intelligent agent) will give action-reaction, observe, and act on a condition so that it looks like itself. In this game, every action or activity is built by the agent to meet the conditions of his environment [16-18]. So here the game agent will be implemented with the finite state machine (FSM) method, where FSM is a control system design methodology that describes the behavior or working principles of the system using state, event, and action $[19,20]$. The game agent involved is in the form of an animated character that can express every step of the player. If the player's move is wrong, the smart agent will have a disappointed expression and vice versa.

\section{RESEARCH METHODOLOGY}

\subsection{Stages Multimedia Development}

According to Binanto (2010), the multimedia development methodology consists of six stages, namely concept, design, material collecting, assembly, testing, and distribution. These six stages cannot swap positions. Even so, the concept stage must indeed be the first thing to do, it can be seen in Figure 1.

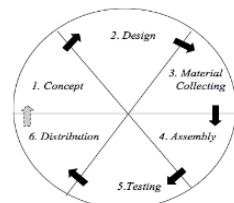

Figure 1. Multimedia Development Stages 


\subsubsection{Concept}

The concept stage (conceptualization) is the stage for determining the objectives and who is the user of the program (audience identification). The goals and end users of the program affect the multimedia nuance as a reflection of the identity of the organization that wants information to reach the end user. User characteristics including user capabilities also need to be considered because they can influence design creation.

In addition, this stage will also determine the type of application (presentation, interactive, etc.) and the purpose of the application (entertainment, training, learning and others). The basic rules for the design are also determined at this stage, for example the size of the application, targets, etc. The output from this stage is usually in the form of a narrative document to reveal the project objectives to be achieved.

\subsubsection{Design}

Design (Design) is the stage of making specifications regarding the program architecture, style, appearance, and material / material requirements for the program. Specifications are made as detailed as possible so that at the next stage, namely collecting and assembly materials, new decision makers are no longer needed, it is enough to use the decisions that have been determined at this stage. However, in practice, project work at an early stage will often experience additional materials or reduction of application parts, or other changes.

\subsubsection{Material Collecting}

Material Collecting is the stage of collecting materials according to the needs that are done. These materials, including clip art images, photos, animation, video, audio, etc., can be obtained freely or by ordering from other parties according to the design. This stage can be done in parallel with the assembly stage. However, in some cases, the material collecting and assembly stages will be carried out linearly and not parallel.

\subsubsection{Assembly}

Assembly stage is the stage of making all multimedia objects or materials. Application development is based on the design stage, flow chart, and / or navigation structure.

\subsubsection{Testing}

Testing phase (testing) is carried out after completing the assembly stage by running the application / program and seeing whether there is an error or not. The first stage at this stage is called the alpha testing stage, where the test is carried out by the manufacturer or the manufacturers own environment. After passing alpha testing, beta testing involving end use will be carried out.

\subsubsection{Distribution}

At this stage, the application will be stored in a storage medium. If the storage media is not sufficient to accommodate the application, compensation for the application will be made. This stage can also be called the evaluation stage for developing finished products to make them better. The results of this evaluation can be used as input for the concept stage of the next product.

\subsection{Design of Finite State Machine (FSM)}

FSM is a control system design that uses three things, namely state, event, and action. This FSM is used to describe the behavior or working principle of the game agent, which can be seen in Figure 2.

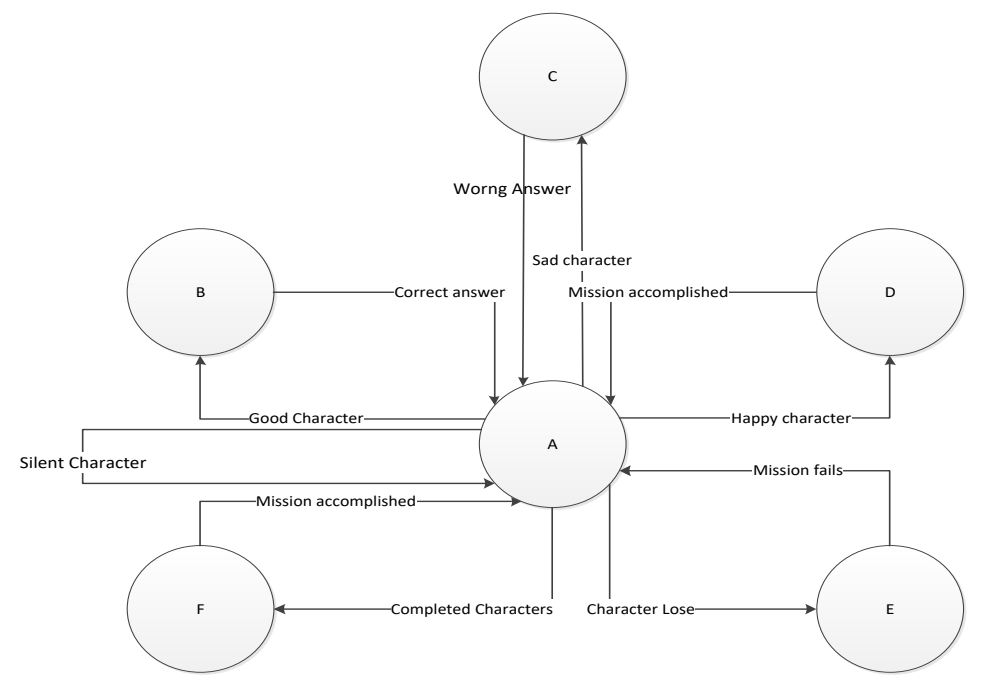

Figure 2. FSM (Finite State Machine) design. 


\section{RESULTS AND DISCUSSION}

\subsection{Scene Initial Display}

In Figure 3 the Initial View scene is the main view of edugame when new players enter the system. There is a name or title from the Edugame "Hangug Word". Every button in the initial scene the scene has their respective functions, when we select start, the main menu scene will be displayed, when we opt out, the yes and no options will be displayed.

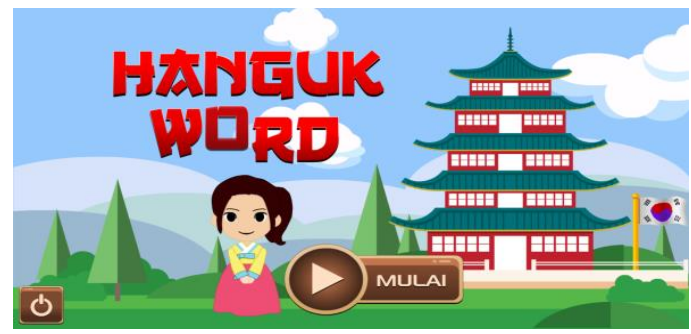

Figure 3. Scene Initial Display

\subsection{Scene Menu Main}

In Figure 4, each button on the main menu scene has its own function, when we select the learning menu, the learning option scene will be displayed, when we select the play menu, the play selection scene will be displayed, when selecting the question menu it will display the question question scene.

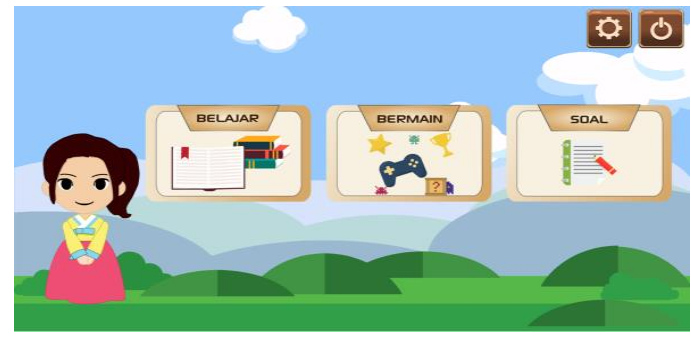

Figure 4. Scene Menu Main

\subsection{Scene Menu Learn}

In Figure 5 the learning scene is a scene where players can choose the option to learn vowels or consonants. And there is a home button to return to the main menu.

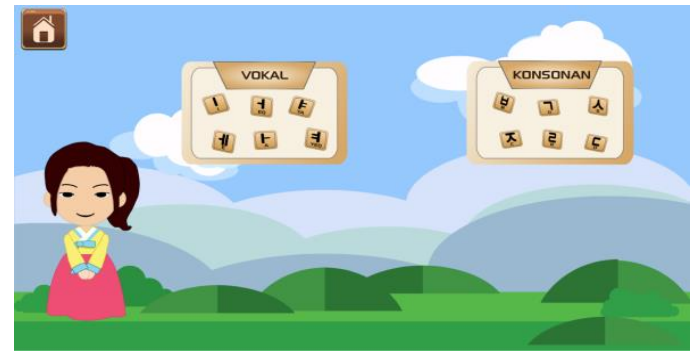

Figure 5. Scene Menu Learn

\subsection{Scene Menu Vowels and Consonants}

In Figures 6 and 7 are the letter learning scenes, where players can learn the form of vowels and consonants and their spelling. So that players can understand and study the content of the existing material, making it easier for players to complete the mission given to the playing scene and questions later.

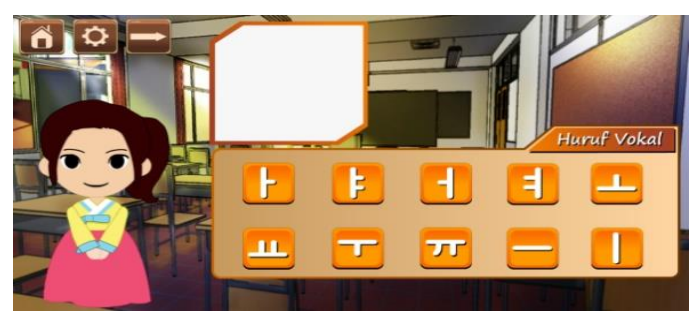

Figure 6. Scene Vowel 


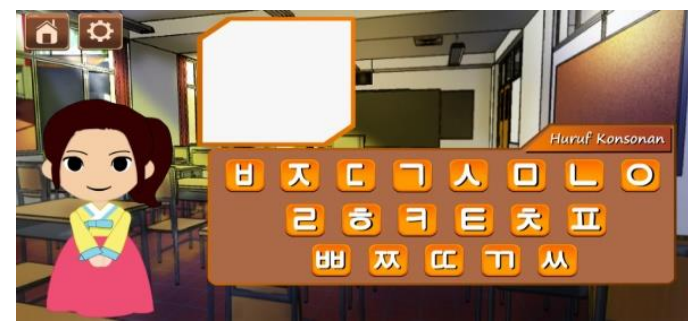

Figure 7. Scene Consonants

\subsection{Scene Menu Played}

In Figure 8 the play menu scene is a scene where players can choose the choice of the game Conam (match names) or Hanlink (compose words). And there is a home button to return to the main menu.

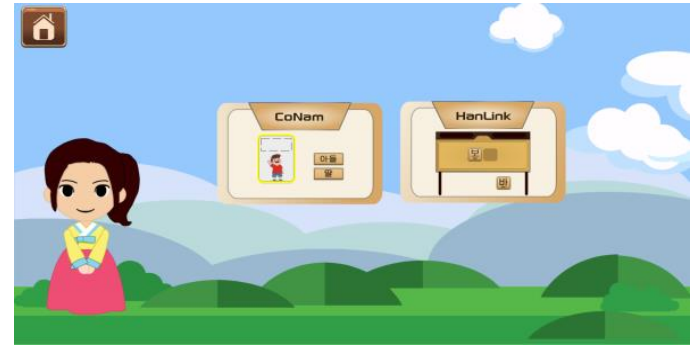

Figure 8. Scene Menu Played

\subsection{Scene Play Conam (Match the Name)}

In Figure 9 the playing scene is a scene where the player plays by completing the mission by matching the word with the object image on the level before the time is over, if the player is successful it will continue to the next level, if you lose then the player can repeat or exit the game.

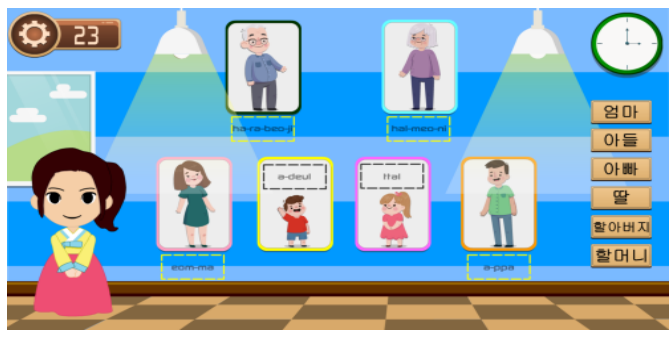

Figure 9. Scene Play Conam (Match Name).

\subsection{Scene Mission accomplished}

In Figure 10, the Mission Success Scene is the scene that will appear if the player successfully completes the mission at one level. In this scene there are also 3 buttons, namely the next button on the left, the refresh button in the middle and the Home button to return to the play menu. And in this scene there are also characters who show happiness when the mission is successfully carried out.

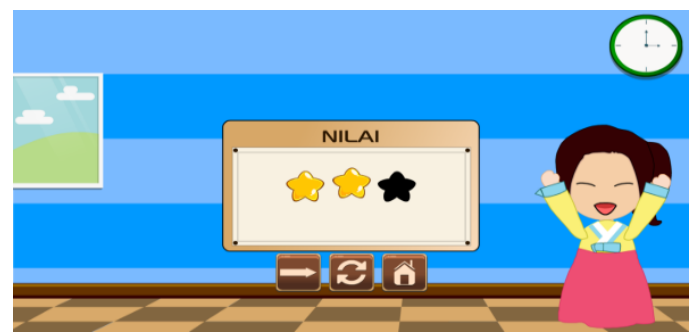

Figure 10. Scene Mission accomplished

\subsection{Scene Mission fails}

In Figure 11 the failed scene is the scene that will appear if you can't complete the mission until time runs out. In this scene, there are two buttons, namely the refresh button to repeat the game that was previously played, and the home button to return to the play menu. And in this scene there is also an animation that shows sadness when the mission fails. 


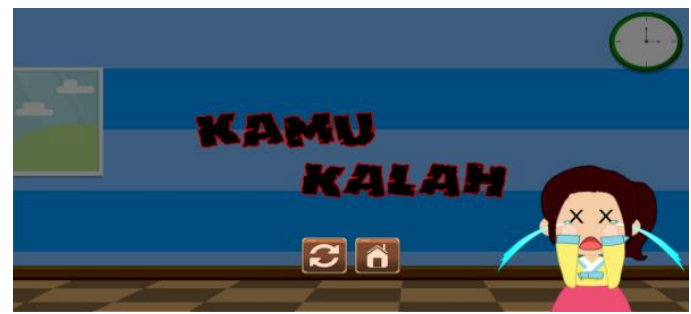

Figure 11. Scene Mission fails

\subsection{Scene The end}

In Figure 12 the finished scene is the scene that will appear if the player has completed all missions. In this scene, there are two buttons, namely the refresh button to repeat the game that was previously played, and the home button to return to the play menu. And in this scene there are also characters who show that they are happy when the mission is completed.

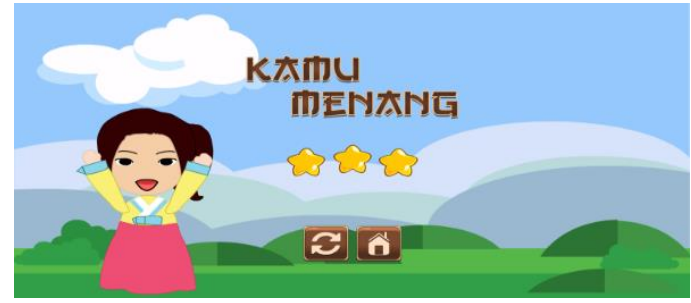

Figure 12. Scene The end

\subsection{Scene Play Hanlink (Hanguk Link)}

In Figure 13 the Hanlink play scene is a scene where players play by completing missions by arranging the Hangul letters below. If the player is successful then it will go to the next level. The character on the left will give a true or false reaction when the player starts composing the letters.

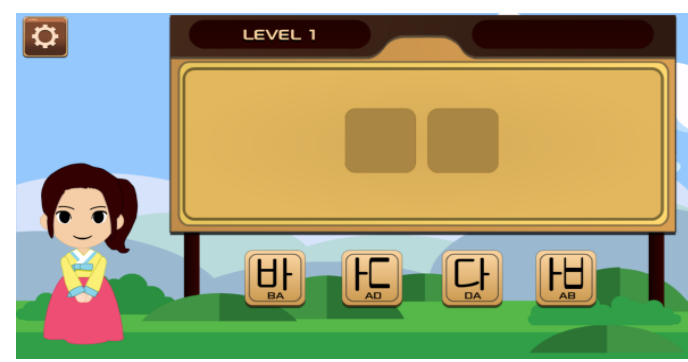

Figure 13. Scene Play Hanlink (Hanguk Link).

\subsection{Scene Mission Accomplished}

In Figure 14 the successful mission scene is the scene that will appear if the player successfully completes the mission at one level. In this scene the player can choose to profit and continue to the next level, can repeat the level that was just played or choose to leave the game.

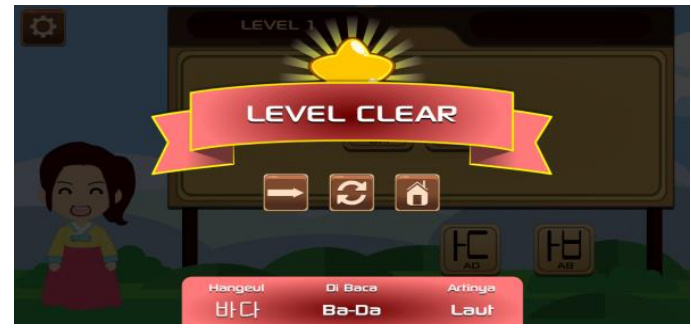

Figure 14. Scene Mission accomplished

\subsection{Scene Question}

In Figure 15 the question scene is a scene where the player will be given questions about vowels, consonants and some random words. When you choose the correct answer, the character will give a happy reaction and if the answer is wrong, the character will react with annoyance and the next question will appear. 


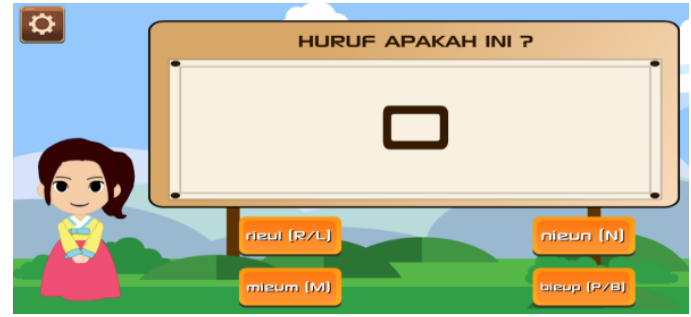

Figure 15.Scene Question

\subsection{Scene Score}

In Figure 16 the value scene is the scene that will display the value of the results obtained after answering the question menu. In this scene there is only one button, namely the home button to return to the main menu.

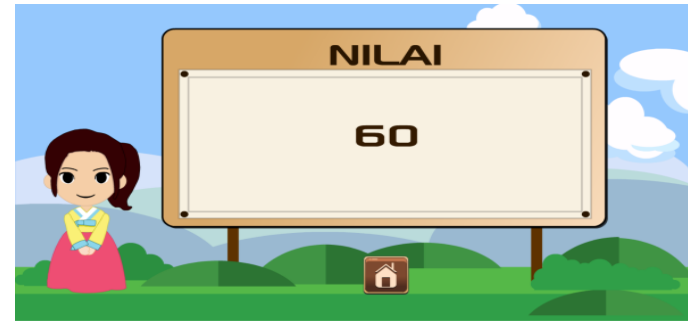

Figure 16.Scene Score

\section{CONCLUSION}

The concept of the "Hangug Word" Edugame Introduction to Korean Hangul Letters is an educational game or game that can help children and adolescents get to know Hangul letters and their spelling, so this learning / edugame media is created. Edugame this uses shuffling the position of the game object or it can be called random shuffle which serves to shuffle objects with the aim that players can not only remember the location of objects in the game. More expressions in the game agent (smart agent) to better interact with the user. There needs to be improvements and additional features so that this game can look more attractive. It is hoped that this game can be used as a reference or reference for informatics students in making their final assignments.

\section{REFERENCES}

[1] K. E. Mi, H. J. Jung, K. H. Yon dan G. Park, "Public Diplomacy and the Overseas Korean Education: A Case Study of Korean Language Education in Indonesia," Humanities and social sciences, no. 47, pp. 43-64, 2015.

[2] U. Hasanah dan R. Nastiti, "Culture Shock and Job Satisfaction of Korean Language Graduates in Korean Corporate Culture in Indonesia," dalam Proceedings of the Proceedings of the First International Seminar on Languare, Literature, Culture and Education, ISLLCE, 15-16 November 2019, Kendari, Indonesia, 2020.

[3] J. Hwan-Seung, "The Korean Wave and Korean Language Education in Thailand," 동남아연구, vol. 17, no. 1, pp. 131168, 2007.

[4] Z. Abidin, Y. Tayo dan . Mayasari, "Fanaticism of a Korean Boy Band, "Shinee" as Perceived by K-Popers "Shinee World Indonesia" in Karawang Regency," International journal of engineering and technology, vol. 7, p. 74, 2018.

[5] J.-Y. Kwon dan S.-S. Lee, "Study of Comparative Lyrics for Joy and Sad Emotions in Korean Popular Songs," The Journal of the Korea Contents Association, vol. 15, no. 3, pp. 68-77, 2015.

[6] J.-Y. Jung, "Application and Need of Korean Popular songs as the Educational Contents," The Journal of the Korea Contents Association, vol. 12, no. 4, pp. 174-185, 2012.

[7] A. Rachmatullah dan M. Ha, "Indonesian and Korean high school student's disparities in science learning orientations: an approach to multi-group structural equation modeling," Asia-Pacific Science Education, vol. 5, no. 1, pp. 1-17, 2019

[8] B. S. Chung dan M. S. Chung, "Homepage to distribute the anatomy learning contents including Visible Korean products, comics, and books," Anatomy \& Cell Biology, vol. 51, no. 1, pp. 7-13, 2018

[9] J.-E. Kim, "A Study on the Correlation between English Word-final Stop and Vowel Duration Produced by Speakers of Korean," Phonetics and Speech Sciences, vol. 3, no. 1, pp. 15-22, 2011.

[10] M. Tadayon dan G. J. Pottie, "Predicting Student Performance in an Educational Game Using a Hidden Markov Model," IEEE Transactions on Education, vol. 63, no. 4, pp. 299-304, 2020.

[11] M. N. Callaghan dan S. M. Reich, "Applying a Developmental Lens to Educational Game Designs for Preschoolers," International Journal of Mobile and Blended Learning, vol. 12, no. 2, pp. 1-15, 2020.

[12] K. Park, B. W. Mott, W. Min, K. E. Boyer, E. N. Wiebe dan J. C. Lester, "Generating Educational Game Levels with Multistep Deep Convolutional Generative Adversarial Networks,” dalam 2019 IEEE Conference on Games (CoG), 2019.

[13] C. Tziortzioti, I. Mavrommati, G. Mylonas, A. Vitaletti dan I. Chatzigiannakis, "Scenarios for Educational and Game Activities using Internet of Things Data," dalam 2018 IEEE Conference on Computational Intelligence and Games (CIG), 2018. 
JURNAL MEDIA INFORMATIKA BUDIDARMA

Volume 5, Nomor 2, April 2021, Page 669-675

ISSN 2614-5278 (media cetak), ISSN 2548-8368 (media online)

Available Online at https://ejurnal.stmik-budidarma.ac.id/index.php/mib

DOI $10.30865 /$ mib.v5i2.2944

[14] A. A. Yunanto, D. Herumurti, I. Kuswadayan, R. R. Hariadi dan S. Rochimah, "Design and Implementation of Educational Game to Improve Arithmetic Abilities for Children," dalam 2019 12th International Conference on Information \& Communication Technology and System (ICTS), 2019.

[15] M. Razakatiana, C. Kolski, R. Mandiau dan T. Mahatody, "Human-agent Interaction based on Game Theory: Case of a road traffic supervision task," dalam 2020 13th International Conference on Human System Interaction (HSI), 2020.

[16] M. Morosan, "Automating Game-design and Game-agent Balancing through Computational Intelligence," Doctoral thesis University Ofessex, 2019.

[17] X. Bo, Game intelligent agent training method and device and equipment and storage medium, Patent Application CN 110882542 A/ 009-567-062-576-588. 2020.

[18] L. Zhao dan K.-C. Chen, "The Game Theoretic Consensus in a Networked Multi-Agent System," dalam 2018 IEEE Global Communications Conference (GLOBECOM), 2018.

[19] M. Mendonca, K. Papageorgiou, D. E. d. Mello, E. I. Papageorgiou, J. A. Fabri, L. B. d. Souza dan R. H. C. Palacios, "Digital game-based learning in a robotics course," dalam 2020 11th International Conference on Information, Intelligence, Systems and Applications (IISA, 2020.

[20] . Emilisa dan R. Darmakusuma, "Virtual Pet Game Application to Train and Manage How to Raise a Cat Well and Properly," dalam 2020 6th International Conference on Interactive Digital Media (ICIDM), 2020. 